SCIREA Journal of Computer

http://www.scirea.org/journal/Computer

February 10, 2022

Volume 7, Issue 1, February 2022

https://doi.org/10.54647/computer52258

\title{
Research on Development Significance and \\ Countermeasures of Virtual Simulation System of Chinese Mine Production
}

\author{
Wang Cuizhi \\ Liaoning Geology Engineering Vocational College, Dandong,118008 Liaoning, China \\ Email: 593388589@qq.com
}

\begin{abstract}
:
This article mainly introduces the significance and restrictive factors of the development and research of mine production virtual simulation system in China, and puts forward the countermeasures to solve and promote the development of mine production virtual simulation system in China.
\end{abstract}

Keywords: Mine production; Virtual simulation system; Industrial revitalization; Professional talents; Research countermeasures

\section{Introduction}

Liaoning Province is the eldest son of the Republic, and industry is the lifeblood of Liaoning. The revitalization of Liaoning first requires industrial revitalization. It is necessary to give full play to the advantages of Liaoning's industrial digitalization scene resources and digital 
industrialization of data resources, to build a digital Liaoning, a smart province, realize the revitalization of Liaoning in the construction of a new development pattern, and to build a new development pattern with Liaoning's revitalization and better services.

In order to realize the "digital butterfly change" in Liaoning, we should cultivate and expand the "new brand", vigorously promote the development of strategic emerging industries, hightech manufacturing and high-tech service industries, vigorously develop the digital economy, and accelerate the cultivation of data element markets and new infrastructure Build, cultivate and expand digital industrial clusters, accelerate the construction of digital government and digital society, and improve the level of artificial intelligence and big data applications.

\section{Development background of mine production virtual simulation system}

\subsection{Industry development background}

The Northeast region is still the center of my country's mining resources. Taking Liaoning as an example, the number of non-coal mines ranks fourth in the country, as shown in Figure 1. Among them, the number of underground mines ranks first in the country, as shown in Figure 2. It can be seen that the development of mineral resources in Liaoning is still an important part of China's mineral resources industry.

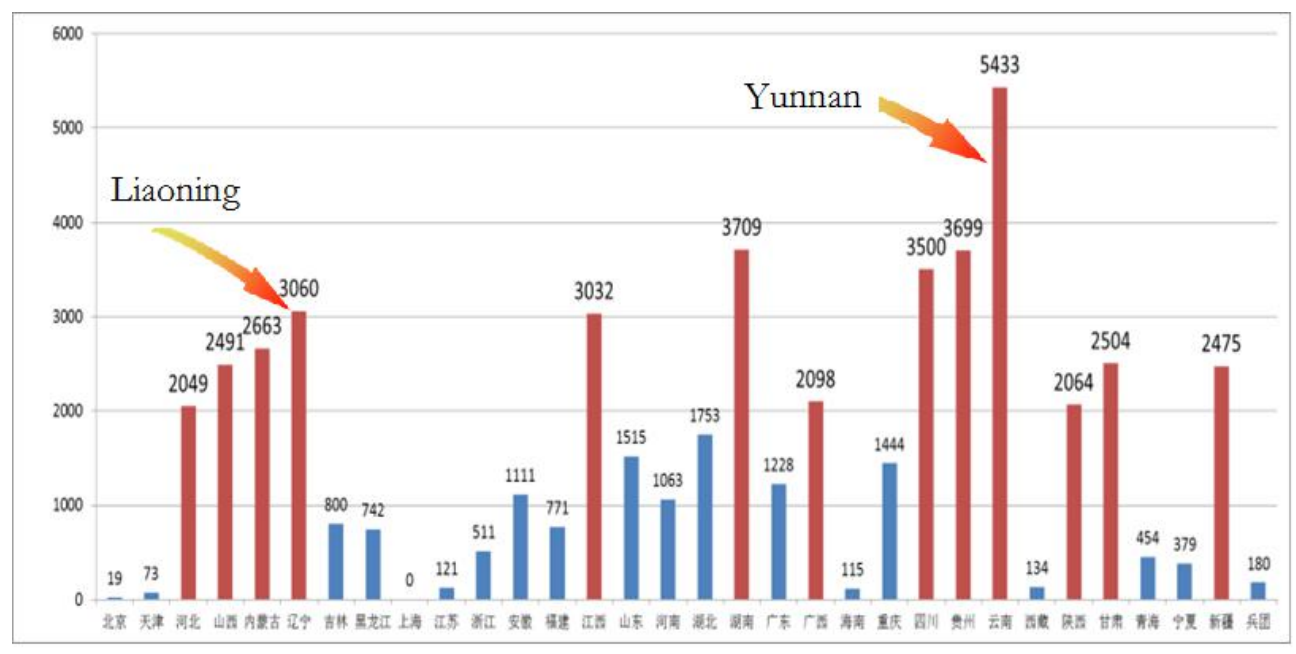

Fig 1 Statistics of non coal mines in China (2016) 


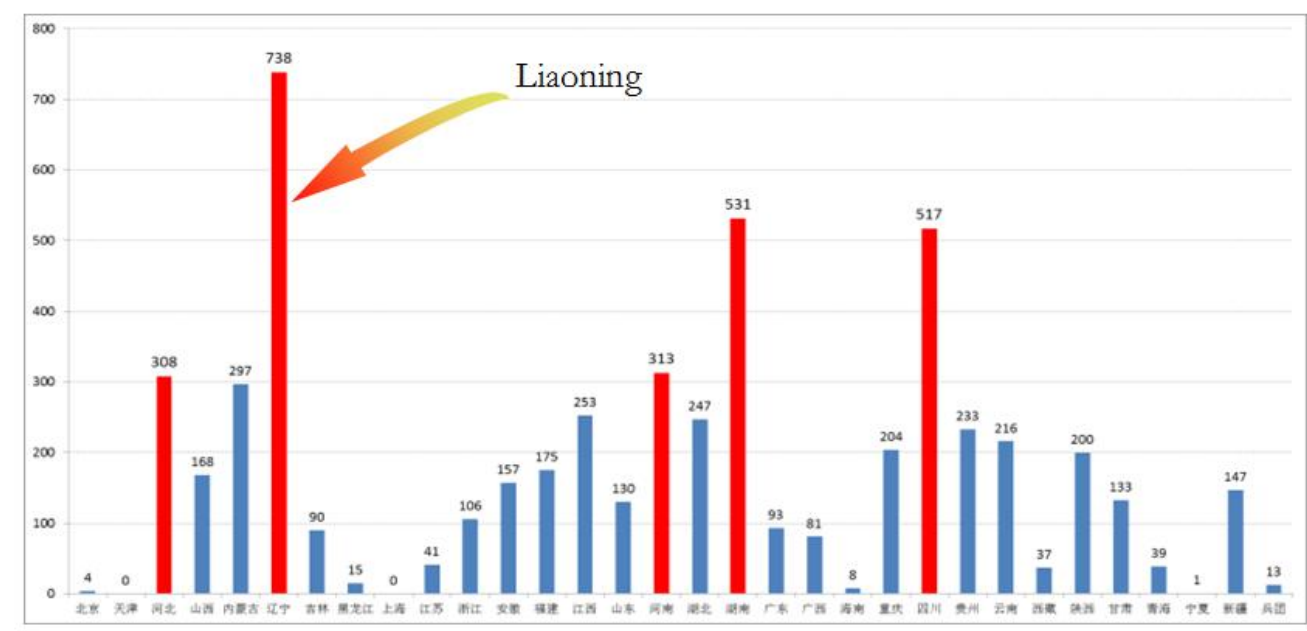

Fig 2 Statistics of underground mines in China (2016)

\subsection{Background of Vocational education}

The education department has begun to implement the digital strategy of rejuvenating Liaoning, requiring vocational colleges to implement the spirit of "digital and intelligent rejuvenation of Liaoning", deepen school-enterprise cooperation, and cultivate talents for enterprises to adapt to the digital age, combined with the "National Vocational Education Reform Implementation Plan" and "Professional "The Action Plan for Education Quality Improvement (2020-2023)" is an important development plan in Liaoning Province.

\subsection{The development of science and technology provides the technical foundation for the} development and construction of the virtual simulation system of mine production

The production of underground mines is characterized by high risk and based on safety factors, which affects and restricts vocational students from going to the mine site for internship and practical training.

At present, the development of modern science and technology has promoted the construction and development of professional skills training platforms, and has provided technical feasibility to meet the special needs of vocational education. The centralized processing of computer informatization can simulate specific teaching scenarios. Intelligent teaching with high-tech electronic information can overcome the limitations of time and space, avoid the dangers in the process of underground mine training, and can also solve the teaching process. The problem of insufficient equipment resources required. 
With the help of science and technology, changing the traditional teaching methods, solving the bottleneck restricting practical teaching, and actively developing the virtual simulation system of mine production is the direction of the development of vocational education.

\section{Current Situation and Significance of Development of Mine Production Virtual System}

\subsection{The Present Situation of Development of Mine Production Virtual System}

(1)Research status of foreign mine virtual simulation teaching

At present, the research on virtual simulation teaching of mine production is very extensive, but in terms of retrieval, it is mainly concentrated in developed countries, and in developed countries, many mining production virtual simulation teaching investment and research tend to be coal mine production systems, and petroleum or Natural gas extraction system, and most of them tend to intelligent extraction machinery and equipment and procedures. Even if there are some for metal mine production, it is limited to open pit mining mines.

(2)Research status of virtual simulation teaching in domestic mines

The research status of virtual simulation teaching in domestic mines is basically similar to that in foreign countries, and most of them tend to mine surveying, mining machinery and other intelligent equipment. Among them, in 2013, the Coal Mine Virtual Mining Simulation Experiment Teaching Center of Henan University of Technology was built, which indeed realized the scene reproduction of the virtual simulation of mine production, and almost realized the whole process of mine production, But it is limited to the experimental teaching system. In addition, Sichuan University has also developed a virtual simulation system for emergency rescue in mines, which has been used in virtual simulation teaching of emergency rescue.

\subsection{Mine production virtual simulation system provides high-quality talents for industrial development}

The development of the national economy is inseparable from the support of mineral resources. At present, due to the dual impact of the slow recovery of the world economy and the adjustment of the national economic structure, the geological industry has entered a new normal. However, the development of mineral resources is still an indispensable basic industry in the construction of the national economy. With the optimization of the economic 
structure and the rapid growth of resources, strengthening the geological exploration of minerals and improving the level of comprehensive utilization of resources has become a major trend in the development of the geological exploration industry.

In recent years, the geological prospecting unit of Liaoning Province has carried out major reforms and established the "Liaoning Geological Exploration and Mining Group Co., Ltd.". At this stage, the current status of the talents in the geological prospecting industry in Liaoning is: the age structure of the staff is relatively large, the professional and technical personnel are few, and the level of high-level personnel There are fewer professional and technical personnel. It is expected that there will be a gap in the future for professional and technical talents in the geological prospecting industry in Liaoning Province.

\subsection{It is the needs of local economic development}

Liaoning region is extremely rich in mineral resources, and now has formed a heavy industry industrial cluster integrating the development and smelting of non-ferrous metals, precious metals and ferrous metal mineral resources. Promoting local economic development must be based on resource development. The quality and lack of geological and mining personnel will restrict the development of the mining economy.

\subsection{It is the future career development needs of students}

Approximately $20-40 \%$ of our students are engaged in mining production every year, and some students have now embarked on mining-level leadership positions. However, due to the particularity of the production of mining enterprises and the state's legal requirements for the production safety of mining enterprises, students cannot directly go deep into mining enterprises to train and practice related practical skills, which limits the training of students' vocational skills to a certain extent.

Combining the particularity of mine production practice and relying on modern virtual simulation technology to realize the virtual reproduction of mine production procedures and practical production skills. Through virtual simulation of scene reproduction, the training and assessment of students' mine production practical skills will be realized, which will enhance students' practical production. The best means of skills.

\section{Restrictive factors in the development of mine virtual simulation system}




\subsection{The foundation of mine virtual simulation system development}

The development of the mine virtual simulation system must have two foundations:

(1) Engineering and technical personnel must be familiar with mine production procedures and possess knowledge and skills of mine production.

(2) Must have the ability to develop a virtual simulation system of Yishou, as well as the ability to process digital technology. In reality, there are very few talents who both possess professional mine production skills and understand the software development of virtual simulation systems. This restricts the development of virtual simulation systems in mines to a certain extent.

\subsection{Lack of motivation for the development of virtual simulation systems for mine production}

The development of mine virtual simulation system requires higher investment costs. In the current world economic situation, with the exception of a few resource minerals with good economic benefits such as coal and oil and gas deposits, other mining products lack strong demand, enterprises and $R \& D$ institutions lack the motivation and enthusiasm for investment.

\subsection{The development of mine virtual simulation system is difficult}

The mining, mining of metal mines underground, has complex geological conditions and complicated mining projects. As a result, the virtual simulation system of the mine must truly fully reflect the production situation and it is very difficult to develop.

\section{Development countermeasures of mine production virtual simulation system}

It is necessary to strengthen the construction of the mine virtual simulation system To truly realize the complete intelligence of mine production.

\subsection{Vocational colleges should strengthen scientific research investment}

The development of science and technology cannot rely on waiting. As vocational colleges, especially mining colleges, they should make a difference in related fields, make overall plans, actively invest, strengthen scientific investment in mine virtual simulation systems, and formulate preferential policies for research and development. 


\subsection{Vocational colleges should make full use of cooperative resources}

In order to make a difference in the development of mine virtual simulation system, As a vocational college, it must closely integrate social resources, unite professional software development enterprises and mine production enterprises to achieve close integration of production, education and research, and jointly develop virtual simulation systems.

\subsection{Strengthen the training of digital technology application talents}

Vocational colleges should strengthen the training of digital technology application talents in their work, pay attention to the development of professional virtual simulation staff's research and development ability and level training, and improve the professional digital technology application level and virtual simulation system development through training, advanced education and scientific research. ability.

\section{Conclusion}

The development and research of the virtual simulation training system for mine production can solve the problem of "invisible, inaccessible, intangible, and difficult to reproduce" practical skills training in underground production sites of mining enterprises, as well as the safety of actual mine training. High cost and other issues, As long as researchers use the computing power and graphics rendering ability of computers as the basis, based on 3D virtual simulation and virtual reality (VR) technology, and with time, a virtual simulation training system for mine production will be developed to promote vocational college students. Teaching quality, and promote the development of mining economy.

\section{Acknowledgements}

The article is one of the achievements of the basic scientific research project of the Liaoning Provincial Department of Education in 2021, "Research on the Development and Application of Virtual Simulation System for Metal Mine Production". It is a project supported by the scientific research fund of the Education Department of Liaoning Province. The research project is presided over by Professor Bao Yuxue of Liaoning Geology Engineering Vocational College. Project number: LJKZ1293. 


\section{References}

[1] Zhang Guoqing. Vigorously promote the construction of digital Liaoning into a smart province [N]; People's Daily; 2021-2

[2] Bai Miaomiao, Mine virtual simulation experiment teaching system, [J] "Metallurgy and Materials", 2020-5

[3] Tu Lixia, Design of Mine Engineering Measurement Accuracy Analysis System Based on Virtual Simulation Technology, [J] "World Nonferrous Metals", 2021-17.

[4] Zhang Yuan, Wan Zhijun, Ma Wending, etc. Discussion on the virtual simulation experiment teaching method of mine pressure and rock formation movement [J] "Laboratory Research and Exploration", 2016-6

[5] Yang Tianhong, Zhang Chunming, Yu Qinglei, etc., Construction and teaching practice of virtual simulation teaching experimental center for rock mechanics and safe mining in metal mines [J] "Education and Teaching Forum", 2019-17.

[6] Liu Bao, Luo Jing, Li Yanfeng, Research on the application of virtual simulation technology in the practical teaching of mining machinery courses $[\mathrm{J}]$ "Education and Teaching Forum" 2019-39

[7] Lv Qinggong, Zhao Zhiyi, Zhang Yankai, etc., Development of Virtual Simulation Practice Teaching System for Metal Mining Practice [J] "China Metallurgical Education", 2019-6

[8] Liu Xiong, Li Haiyang, Jiang Xugang, Design and implementation of mine rescue medical emergency training system based on 3D virtual simulation technology [J] "Mining Safety and Environmental Protection" Peking University Core, 2018-1.

[9] Application of Zhi Fubiao 3D virtual simulation technology in mine emergency rescue system [J] "Journal of Hebei Energy Vocational and Technical College", 2017-1

[10] Huang Bin, The application and prospect of virtual simulation technology in the design and manufacture of mining machinery [J] "China Metal Bulletin" 2020-19

[11] Huang Shaohua, The application and prospect of virtual simulation technology in the design and manufacture of mining machinery [J] 《World Nonferrous Metals》2018-3

[12] Hou Jianming, Yang Junyan-. Mine rescue virtual simulation exercise system developed based on virtual reality technology [J] "Mining Safety and Environmental Protection" Peking University Core, No. 5, 2018

[13] Wang Jing, Liu Peizheng, Zhang Peng, etc., Virtual mine simulation development under Unity3D software [J] "Modern Mining", 2019-5 
[14] Wang Wentian, Guan Changliang, Liu Qichao, etc., Discussion on the application of virtual simulation technology in the construction of smart mines [J] "China Mining Engineering", 2017-5

[15] Ren Jianxi, Chen Xinnian, Gu Shuancheng, Zhang Kun, Li Qiang, Zhi Bin, Deng Botuan, Qiu Jisheng, Research on Resource Construction Practice of Virtual Simulation Experiment Teaching Center for Mining Construction Engineering [S] 2016 National Experimental Teaching Demonstration Center Construction Seminar in Higher Education Institutions Conference and Virtual Simulation Technology and Teaching Resources Construction Forum,2016. 